\title{
Crescimento e produção do pinhão-manso irrigado com água residuária sob condições de estresse hídrico ${ }^{1}$
}

\author{
Maria B. R. Silva'2, Pedro D. Fernandes'2, José D antas N eto², Aparecida R. N ery², \\ Luis N. Rodrigues ${ }^{2} \&$ Ricardo A. Viégas $^{3}$
}

\begin{abstract}
RESU MO
O pinhão-manso é uma espécie nativa do Brasil, da família das Euforbiáceae. O bjetivou-se, com esta pesquisa, estudar os efeitos de diferentes níveis de reposição da evapotranspiração sob as variáveis de crescimento e produção do pinhão-manso irrigado com efluente de esgoto doméstico. 0 experimento foi desenvolvido em lisímetros de drenagem sob ambiente protegido. 0 delineamento estatístico utilizado foi em blocos casualizados, com quatro repetições; estudaram-se cinco níveis de reposição de água $\left(\mathrm{Nr}_{1}=0,25 ; \mathrm{Nr}_{2}=0,50 ; \mathrm{Nr}_{3}=0,75, \mathrm{Nr}_{4}=1,00\right.$ e $\mathrm{Nr}_{5}=1,25$ da evapotranspiração) e a altura das plantas, o diâmetro caulinar, o número de folhas, a área foliar e 0 número de cachos. $\mathrm{A}$ unidade experimental foi constituída pela média de duas plantas cultivadas em lisímetros separados. 0 solo utilizado como substrato foi um Argissolo não-salino, franco-arenoso. As irrigações foram realizadas a cada dois dias e o volume de água aplicado em cada tratamento foi determinado através de balanço hídrico, tomando-se por base o nível $\mathrm{Nr}_{4}, 100 \%$ de reposição da evapotranspiração. 0 estresse hídrico ocasionou efeito significativo em todas as variáveis estudadas, indicando sensibilidade do pinhãomanso ao baixo teor de umidade do solo.
\end{abstract}

Palavras-chave: Jatropha curcas L., irrigação, número de cachos

\section{Growth and production of physic nut irrigated with wastewater, under water stress conditions}

\section{ABSTRACT}

The physic nut is a Brazilian native crop of the Euforbiaceae family. The objective of this study was to evaluate the effects of different levels of the evapotranspiration replacement on the growth and production variables of the crop irrigated with domestic sewage. The experiment was carried out in drainage lysimeters under controlled environment. A statistical scheme in randomized block was utilized with four repetitions and five water replacement levels $\left(\mathrm{Nr}_{1}=0.25 ; \mathrm{Nr}_{2}=0.50 ; \mathrm{N} \mathrm{r}_{3}=0.75, \mathrm{~N} \mathrm{r}_{4}=1.00\right.$ and $\mathrm{Nr}_{5}=1.25$ of evapotranspiration). Plant height, stem diameter, number of leaves, leaf area and the number of fruit bunches were observed. The soil used as substrate was an Argisol, sandy loam non saline. The irrigation was realized at two days interval and the quantity of water applied in each treatment was determined from water balance in function of $\mathrm{N}_{4}$ level. At the end of the study it was verified that the water stress caused significant effect in all studied variables, which indicates the sensibility of the crop to the low water content in the soil.

Key words: Jatropha curcas L., irrigation, number of bunch

Parte da Tese de Doutorado do primeiro autor, apresentada ao Programa de Pós-Graduação em Engenharia Agrícola/UFCG

U AEA/U FCG. Av. Aprígio Veloso 882, CEP 58429-140. Campina Grande, PB. Fone: (83) 3310-1285. E-mail (s): betaniars@hotmail.com; pdantas@pesquisador.cnpq.br; zedantas@deag.ufcg.edu.br; cydanery@gmail.com; luis.lunero@gmail.com U AEF/U FCG. Rua PB 110, Jatobá, CEP 58700-970. Patos, PB. E-mail: raviegas@uol.com.br 


\section{INTRODUÇÃO}

Atualmente, os óleos vegetais têm sido largamente estudados como alternativas para programas de energia renovável, uma vez que proporcionam uma geração descentralizada de energia. O cultivo de espécies oleaginosas constitui alternativas em apoio à agricultura familiar, criando melhores condições de vida em regiões carentes, valorizando potencialidades regionais e oferecendo alternativas a problemas econômicos e sócio-ambientais (Ramos et al., 2003).

O pinhão-manso (Jatropha curcas L.) uma planta produtora de óleo e bem adaptada a diversas regiões do Brasil, pertence à família Euphorbiaceae. Segundo Arruda et al. (2004) sua distribuição geográfica é bastante vasta, devido à sua rusticidade, resistência a longas estiagens, sendo adaptável a condições edafoclimáticas muito variáveis, desde a região Nordeste, Sudeste e o estado do Paraná.

As perspectivas favoráveis da implantação racional dessa cultura decorrem não somente dos baixos custos de sua produção agrícola, conforme se deve esperar diante das vantagens anunciadas mas, sobretudo, porque poderá ocupar solos pouco férteis, de modo geral inaptos à agricultura de subsistência proporcionando, desta maneira, uma nova opção econômica às regiões carentes do país, principalmente na agricultura familiar (Akbar et al., 2009).

Devido à demanda energética sempre crescente em todo o mundo, as prioridades se voltam para fontes energéticas renováveis destacando-se, dentre elas, o pinhão-manso como excelente alternativa, diminuindo os impactos negativos de combustíveis originados do petróleo sobre o meio ambiente. É uma nova opção que se abre para a geração de emprego e renda no meio rural e matéria-prima para a obtenção de produtos necessários ao desenvolvimento da indústria de biodiesel.

Considerando a pressão cada vez mais crescente por águas de boa qualidade em todo o mundo, nos últimos anos vários fatores contribuíram para o aumento do interesse pela irrigação com efluentes, dentre eles a escassez de recursos hídricos, o avanço do conhecimento técnico-científico em relação ao potencial que representa o reúso de esgotos e as limitações do reúso agrícola; considerem-se, também, outras vantagens, como controle da poluição ambiental, economia de água e fertilizantes, reciclagem de nutrientes e aumento da produção agrícola. O interesse pelo reúso planejado, ou seja, o uso seguro do ponto de vista de contaminação e controlado do ponto de vista agrícola surgiu do próprio reconhecimento da importância do controle da utilização de esgotos na agricultura, com o objetivo de impedir o uso sem critério definido (Villela Júnior et al., 2003).

Apesar do pinhão-manso ser considerada uma espécie que sobrevive em condições de seca, adaptada à semiaridez, exigente em calor e luminosidade, a garantia de produção deverá ser maior com irrigação, sendo escassas na literatura disponível, informações sobre suas exigências hídricas e o efeito de águas de qualidade inferior, na sua produção. Objetivou- se, com esta pesquisa, estudar os efeitos da aplicação de diferentes níveis de reposição da evapotranspiração, através da irrigação com água residuária de esgoto doméstico no crescimento e produção das plantas.

\section{Material E MÉTODOS}

O experimento foi conduzido em instalações pertencentes à Universidade Federal de Campina Grande (UFCG), Centro de Tecnologia e Recursos Naturais (CTRN), Unidade Acadêmica de Engenharia Agrícola (UAEA), sob condições de ambiente protegido, durante o período de maio de 2007 a maio de 2008, com as seguintes coordenadas geográficas: latitude $07^{\circ} 13^{\prime} \mathrm{S}$, longitude $35^{\circ} 53^{\prime} \mathrm{W}$ e altitude média $550 \mathrm{~m}$.

As mudas foram produzidas em tubetes $\left(200 \mathrm{~cm}^{3}\right)$, na UFCG, utilizando-se sementes da variedade FT- 02, cedidas pelo Instituto Fazenda Tamanduá, localizado no município de Santa Terezinha, PB. A semeadura foi realizada após seleção e eliminação de sementes defeituosas e após a realização do teste de germinação. Os tubetes foram preenchidos com substrato orgânico esterilizado, aproximadamente a uma profundidade de $2 \mathrm{~cm}$. Foram utilizados 40 lisímetros de drenagem, com capacidade de $200 \mathrm{~L}$ ( $\mathrm{D}=0,58 \mathrm{~m} \mathrm{e} \mathrm{h}=75 \mathrm{~cm}$ ); o sistema de drenagem foi composto de tela de nylon, 5,0 L de brita, 5,0 L de areia, mangueira e dois recipientes coletores de $2 \mathrm{~L}$.

Na Tabela 1 estão os dados da análise físico-hídrica e química do solo, realizada no Laboratório de Irrigação e Salinidade da Universidade Federal de Campina Grande, conforme metodologia proposta pela EMBRAPA(1997).

Tabela 1. Características físico-hídricas e químicas do solo utilizado na pesquisa

\begin{tabular}{|c|c|c|}
\hline Atributo físico-hídrico & Unidade & Valor \\
\hline $\begin{array}{l}\text { Areia } \\
\text { Silte } \\
\text { Argila } \\
\text { Classificação textural } \\
\text { Densidade do solo (ds) } \\
\text { Densidade das partículas (dp) } \\
\text { Porosidade }(\varepsilon) \\
\text { Capacidade de campo (10,13 kPa) (CC) } \\
\text { Ponto de murchamento (1519,87 kPa) (PM) } \\
\text { Água disponível (AD) }\end{array}$ & $\begin{array}{l}\mathrm{g} \mathrm{kg}^{-1} \\
\mathrm{~g} \mathrm{~kg}^{-1} \\
\mathrm{~g} \mathrm{~kg}^{-1} \\
- \\
\mathrm{g} \mathrm{cm}^{-3} \\
\mathrm{~g} \mathrm{~cm}^{-3} \\
\% \\
\mathrm{~g} \mathrm{~kg}^{-1} \\
\mathrm{~g} \mathrm{~kg}^{-1} \\
\mathrm{~g} \mathrm{~kg}^{-1}\end{array}$ & $\begin{array}{c}733 \\
84 \\
183 \\
\text { Franco arenoso } \\
1,60 \\
2,75 \\
41,82 \\
82,00 \\
20,50 \\
61,50\end{array}$ \\
\hline Atributo químico & Unidade & $\begin{array}{c}\text { Valor }^{1} \\
\text { Antes - Após }\end{array}$ \\
\hline $\begin{array}{l}\text { Cálcio }\left(\mathrm{Ca}^{+2}\right) \\
\text { Magnésio }\left(\mathrm{Mg}^{+2}\right) \\
\text { Sódio }\left(\mathrm{Na}^{+}\right) \\
\text {Potássio }\left(\mathrm{K}^{+}\right) \\
\text {Soma de bases (S) } \\
\text { Hidrogênio }\left(\mathrm{H}^{+}\right) \\
\text {Alumínio }\left(\mathrm{Al}^{+3}\right) \\
\text { Capacidade de troca catiônica (CTC) } \\
\text { Saturação de bases (V) } \\
\text { Percentagem de sódio trocável (PST) } \\
\text { Carbono orgânico (C-Org.) } \\
\text { Matéria orgânica (M.O. = 1,724*C-Org.) } \\
\text { Nitrogênio (5 \% M.O.) (N-Org.) } \\
\text { Fósforo assimilável (P) } \\
\text { pH em água }(1: 2,5)(\mathrm{pH}) \\
\mathrm{CE} \text { da suspensão solo-água (1:2,5) (CEsa) }\end{array}$ & 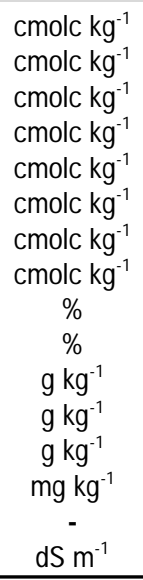 & $\begin{array}{c}0,67-1,25 \\
1,19-1,55 \\
0,03-0,03 \\
0,07-0,30 \\
1,96-3,13 \\
0,55-0,20 \\
0,80-0,05 \\
3,31-3,38 \\
59,21-92,60 \\
0,91-0,89 \\
1,10-1,10 \\
1,90-1,90 \\
0,09-0,09 \\
0,10-81,60 \\
5,20-6,18 \\
0,19-0,29 \\
\end{array}$ \\
\hline
\end{tabular}

Análise realizada no Laboratório de Irrigação e Salinidade, UFCG/UAEA/CTRN

${ }^{1}$ Análise realizada antes e 24 dias após a calagem

Em cada lisímetro foram colocados cerca de $230 \mathrm{~kg}$ de material de solo devidamente destorroado, adubado e corrigido, conforme resultados da análise química (Tabela 1). Os 
procedimentos de calagem seguiram a metodologia proposta pela Embrapa CNPA, para a cultura da mamoneira (Beltrão et al., 2003).

O material de solo foi proveniente do Distrito de São José da Mata (Campina Grande, PB), classificado como Argissolo Acinzentado Eutrófico e coletado na profundidade de $0-30 \mathrm{~cm}$ (horizonte A). Verificam-se, na Tabela 1, as características químicas do solo antes e vinte quatro dias após a prática de calagem.

$\mathrm{O}$ cálculo da necessidade de calcário (NC) foi obtido considerando-se os resultados da análise química do solo e o método que resultou em maior necessidade de calcário (elevação das bases trocáveis), Novais et al. (1991). De acordo com os resultados apresentados na Tabela $1\left(\mathrm{Al}^{+3}=0,80\right.$ cmolc kg-1 $\mathrm{Ca}^{+2}+\mathrm{Mg}^{+2}=1,86$ cmolc kg-1 e, V = 59,21\%) e do calcário dolomítico com $\mathrm{PRNT}=72,50 \%(\mathrm{~F}=1,38)$, pelo critério de elevação das bases trocáveis $\left(\mathrm{NC}\left(\mathrm{t} \mathrm{ha}^{-1}\right)=\left[2,0 \times \mathrm{Al}^{+3}+(2,0-\right.\right.$ $\left.\left.\left.\left(\mathrm{Ca}^{+2}+\mathrm{Mg}^{+2}\right)\right)\right] \times \mathrm{F}\right)$, a necessidade de calcário foi de 75,00 g para cada $100 \mathrm{~kg}$ de solo (Novais et al., 1991). Na adubação de plantio foi adotada a metodologia de Novais et al. (1991) para experimentos conduzidos em ambiente protegido: 300,100 , e $150 \mathrm{mg} \mathrm{kg}^{-1} \mathrm{de}_{2} \mathrm{O}_{5}, \mathrm{~N}$, e $\mathrm{K}_{2} \mathrm{O}$, respectivamente.

$\mathrm{O}$ transplantio das mudas foi realizado seis dias após a calagem, 19 dias após a semeadura - DAS. Em cada lisímetro foi transplantada uma muda previamente selecionada de maneira homogênea conforme seu vigor. As mudas transplantadas foram irrigadas diariamente, mantendo-se o solo em condições de capacidade de campo, de maneira a promover maior rapidez na reação do calcário. Aárea experimental foi instalada no lado direito do Riacho Bodocongó (UFCG), Campina Grande, PB, de onde foi captada a água residuária de esgoto bruto para a irrigação, obedecendo-se a um turno de rega de dois dias.

Para a coleta da água residuária foi utilizado um sistema composto de um recipiente de PVC com capacidade para $250 \mathrm{~L}$ com paredes perfuradas e envolvido por tela de malha de $1 \mathrm{~mm}$, motobomba anauger submersa ('bomba sapo') com potência de $370 \mathrm{~W}$, tubulação de recalque com mangueira de polietileno $3 / 4$ e reservatório com capacidade de $1000 \mathrm{~L}$, onde era armazenada a água para a irrigação.

Antes de se iniciar as irrigações, todos os lisímetros foram colocados em capacidade de campo. Na primeira irrigação foi aplicado, em todos os lisímetros/tratamentos, um volume de apenas $2 \mathrm{~L}$, visto que o solo se encontrava em capacidade de campo; posteriormente, o manejo das irrigações foi realizado através de balanço hídrico utilizando-se planilha eletrônica. Durante o período experimental amostras de água residuária foram coletadas e analisadas no Laboratório de Irrigação e Salinidade - LIS, seguindo-se a metodologia proposta por Richards (1977), Tabela 2.

A aplicação dos tratamentos se iniciou 37 dias após a semeadura - DAS (18 dias após o transplantio - DAT). A condução do experimento ocorreu nos meses de maio/2007 a maio/2008. Foram estudados 5 níveis de reposição de água $\left(\mathrm{Nr}_{1}=0,25 ; \mathrm{Nr}_{2}=0,50 ; \mathrm{Nr}_{3}=0,75 ; \mathrm{Nr}_{4}=1,00\right.$ e $\mathrm{Nr}_{5}=1,25 \mathrm{da}$ evapotranspiração). O experimento foi distribuído em blocos casualizados, com quatro repetições, sendo a parcela constituída de 2 plantas ( 1 planta/lisímetro), perfazendo o total de 40 lisímetros (5 níveis de reposição da evapotranspiração x
Tabela 2. Características físico-químicas da água residuária utilizada nas irrigações

\begin{tabular}{|c|c|c|c|c|}
\hline \multirow{2}{*}{ Características } & \multicolumn{3}{|c|}{ Amostra } & \multirow{2}{*}{ - Média } \\
\hline & 1 & 2 & 3 & \\
\hline $\mathrm{pH}$ & 7,38 & 7,51 & 6,89 & 7,26 \\
\hline Condutividade elétrica ( $\mathrm{dS} \mathrm{m}^{-1}$ ) & 1,30 & 1,10 & 1,56 & 1,32 \\
\hline Cálcio $\left(\mathrm{mg} \mathrm{L}^{-1}\right)$ & 42,80 & 67,00 & 54,25 & 54,68 \\
\hline Magnésio (mg L $\left.{ }^{-1}\right)$ & 48,04 & 45,84 & 39,84 & 44,57 \\
\hline Sódio $\left(\mathrm{mg} \mathrm{L}^{-1}\right)$ & 137,08 & 109,48 & 116,76 & 121,11 \\
\hline Potássio (mg L-1 $)$ & 26,52 & 23,40 & 28,76 & 26,23 \\
\hline Cloreto $\left(\mathrm{mg} \mathrm{L}^{-1}\right)$ & 187,88 & 159,52 & 132,85 & 160,08 \\
\hline Sulfato (mg L $\left.{ }^{-1}\right)$ & 62,40 & 58,35 & 54,55 & 58,43 \\
\hline Bicarbonato $\left(\mathrm{mg} \mathrm{L}^{-1}\right)$ & 491,05 & 412,97 & 554,08 & 486,03 \\
\hline Carbonato $\left(\mathrm{mg} \mathrm{L}^{-1}\right)$ & 33,00 & 37,80 & 30,54 & 33,78 \\
\hline Ferro $\left(\mathrm{mg} \mathrm{L}^{-1}\right)$ & 0,55 & 1,28 & 0,49 & 0,77 \\
\hline Oxigênio consumido $\left(\mathrm{mg} \mathrm{L}^{-1}\right)$ & 27,50 & 21,07 & 19,85 & 22,81 \\
\hline Alcalinidade em carbonato (mg L ${ }^{-1}$ ) & 55,00 & 62,00 & 57,43 & 58,14 \\
\hline Alcalinidade em bicarbonato $\left(\mathrm{mg} \mathrm{L}^{-1}\right)$ & 402,50 & 389,42 & 414,32 & 402,08 \\
\hline Alcalinidade total $-\mathrm{CaCO}_{3}\left(\mathrm{mg} \mathrm{L}^{-1}\right)$ & 457,50 & 359,36 & 328,75 & 381,87 \\
\hline Dureza total - $\mathrm{CaCO}_{3}\left(\mathrm{mg} \mathrm{L}^{-1}\right)$ & 290,82 & 275,32 & 283,18 & 283,11 \\
\hline $\begin{array}{l}\text { Relação de adsorção de sódio (RAS) } \\
\left(\mathrm{mmol} \mathrm{L}^{-1}\right)^{1 / 2}\end{array}$ & 3,40 & 1 & 2 & 95 \\
\hline Classe da água & $\mathrm{C} 3$ & $\mathrm{C} 3$ & C3 & C3 \\
\hline
\end{tabular}

Análise realizada no Laboratório de Irrigação e Salinidade, UFCG/UAEA/CTRN

4 blocos x 2 lisímetros). Adotou-se o espaçamento de 1,70 x 1,40 $\mathrm{m}$ das parcelas experimentais dentro do bloco e 1,60 m entre blocos.

Os tratos culturais consistiram de adubações de cobertura, adubações foliares e eliminação de folhas não funcionais das plantas. As adubações de cobertura foram feitas durante o período experimental em intervalos de duas semanas, aplicandose sulfato de amônia - $\left(\mathrm{NH}_{4}\right)_{2} \mathrm{SO}_{4}$ e cloreto de potássio - $\mathrm{KCl}$ nas plantas. Aos 95 dias após o transplantio foi feita a primeira adubação de cobertura, sendo aplicados $3 \mathrm{~g}$ de $\left(\mathrm{NH}_{4}\right)_{2} \mathrm{SO}_{4}+4 \mathrm{~g}$ $\mathrm{KCl}$ por planta; posteriormente, foi seguido um calendário. Aos 109 DAT (3g de $\left.\left(\mathrm{NH}_{4}\right)_{2} \mathrm{SO}_{4}+4 \mathrm{~g} \mathrm{KCl}\right)$; 123, 137 e $151 \mathrm{DAT}$ (3g de $\left.\left(\mathrm{NH}_{4}\right)_{2} \mathrm{SO}_{4}\right) ; 165$ e $179 \mathrm{DAT}\left(3 \mathrm{~g} \mathrm{de}\left(\mathrm{NH}_{4}\right)_{2} \mathrm{SO}_{4}+4 \mathrm{~g} \mathrm{KCl}\right) ; 193,207$ e 221 DAT (3g de $\left.\left(\mathrm{NH}_{4}\right)_{2} \mathrm{SO}_{4}\right) ; 235$ e 249 DAT $\left(3 \mathrm{~g} \mathrm{de}\left(\mathrm{NH}_{4}\right)_{2} \mathrm{SO}_{4}\right.$ $+4 \mathrm{~g} \mathrm{KCl}) ; 263,277$ e 291 DAT $\left(3 \mathrm{~g}\right.$ de $\left.\left(\mathrm{NH}_{4}\right)_{2} \mathrm{SO}_{4}\right) ; 305$ e 319 DAT $\left(3 \mathrm{~g}\right.$ de $\left.\left(\mathrm{NH}_{4}\right)_{2} \mathrm{SO}_{4}+4 \mathrm{~g} \mathrm{KCl}\right) ; 333,347,361$ e 375 DAT $(3 \mathrm{~g}$ de $\left.\left(\mathrm{NH}_{4}\right)_{2} \mathrm{SO}_{4}\right)$, conforme recomendação de Novais et al. (1991).

As adubações foliares foram feitas com uma solução de zinco + cobre $(0,05 \%)$, visando ao controle dos sintomas de deficiência de zinco e cobre, principalmente o encarquilhamento. Além da aplicação de albatrós 1,80g L $\mathrm{L}^{-1}(\mathrm{~N}-\mathrm{P}-\mathrm{K}$ - Mg: 7-1735-3, + micronutrientes).

Verificou-se, ao longo do experimento, ataque de cigarrinha verde (Empoasca kraemeri), mosca branca (Bemisia tabaci) ácaro branco (Polyphagotarsonemus latus) e ácaro vermelho (Tetranychus desertorum). O controle do ácaro foi realizado através da aplicação do acaricida, cujo ingrediente ativo é conhecido como Abamectina + óleo vegetal Agro-oil. A cigarrinha verde foi controlada com o extrato do próprio pinhãomanso, obtendo-se $100 \%$ do controle.

Foram analisadas as variáveis altura das plantas, diâmetro caulinar, número de folhas e área foliar a cada 42 dias, aos 60 , 102, 144, 186, 228, 270, 312, 354 e 396 DAT. A altura das plantas foi obtida com fita métrica $(\mathrm{cm})$, considerando-se a distância entre o colo da planta e a extremidade do broto terminal do 
ramo principal. O diâmetro caulinar $(\mathrm{mm})$ foi determinado no colo da planta a uma altura aproximada de $3 \mathrm{~cm}$, utilizando-se um paquímetro. O número de folhas de cada planta foi obtido através da contagem, considerando-se as folhas com tamanho aproximado acima de $3 \mathrm{~cm}$. Para a determinação da área foliar por planta foi adotada a metodologia proposta por Severino et al. (2007). O número de cachos/planta foi determinado através da identificação de cada cacho com um cordão, no final da produção, foi feita sua contagem obtendo-se o número de cachos por planta.

Os dados foram submetidos às análises de variância e de regressão polinomial, utilizando-se do software estatístico SISVAR-ESAL (Lavras, MG). Os graus de liberdade dos tratamentos com ' $\mathrm{Nr}$ ' foram decompostos em componentes de regressão polinomial em virtude de se tratar de fator quantitativo; adotou-se, para a construção das curvas, o maior grau de regressão significativo (Ferreira, 2000). Para a componente de produção número de cachos, a curva foi feita através de Exponencial (X), melhor modelo de ajuste dos dados.

\section{RESULTADOS E DisCUSSÃO}

\section{Altura de plantas (AP)}

Ocorreu efeito significativo dos níveis de reposição da evapotranspiração (Nr), na altura de plantas (AP), em todos os períodos estudados, exceto aos 18 dias após o transplantio, período de início dos tratamentos (Figura 1). Com base nessas informações, pode-se afirmar a sensibilidade da espécie Jatropha às condições de estresse hídrico. Rodrigues et al. (2009), estudando a cultura da mamona verificou que a altura das plantas foi afetada quando irrigadas com $60 \%$ da evapotranspiração.

Na Figura 1 são apresentados os valores médios da altura de plantas em diferentes estádios de desenvolvimento; verificase que o modelo que melhor se ajustou aos dados da variável AP foi o linear, dos 60 DAT até o último período estudado (396 DAT); observa-se, na Figura 1A, aos 18 DAT, efeito não significativo dos tratamentos. Conforme a Figura 1A, aos 60 dias após o transplantio, aplicando-se o modelo linear para altura de plantas, houve um aumento de $0,2245 \mathrm{~cm}(0,44 \%)$ na variável altura da planta, por cada centésimo de incremento da evapotranspiração.

Analisando-se o comportamento dessa variável nos períodos 102 e 144 DAT (Figura 1B), 186 e 228 DAT (Figura 1C), 270 e 312 DAT (Figura 1D), 354 e 396 DAT (Figura 1E), constata-se que para cada centésimo de incremento da evapotranspiração ocorreu um aumento de 0,4215 e 0,526, 0,6015 e $0,725,0,783$ e $0,922,1,017$ e $1,1125 \mathrm{~cm}$, respectivamente, na altura das plantas. Em termos percentuais, este aumento equivale a $0,48,0,51,0,53,0,63,0,64,0,72,0,74$ e $0,77 \%$.

$\mathrm{O}$ incremento do suprimento hídrico ocasionou um crescimento maior em altura das plantas durante todo o período estudado. Pelos resultados apresentados (Figura 1), a melhor resposta na altura das plantas de pinhão-manso ocorreu nos tratamentos de maior nível de reposição da ETc, indicando que o pinhão-manso é uma cultura sensível ao estresse hídrico. Para Taiz \& Zeiger (2004), muitos processos fisiológicos das
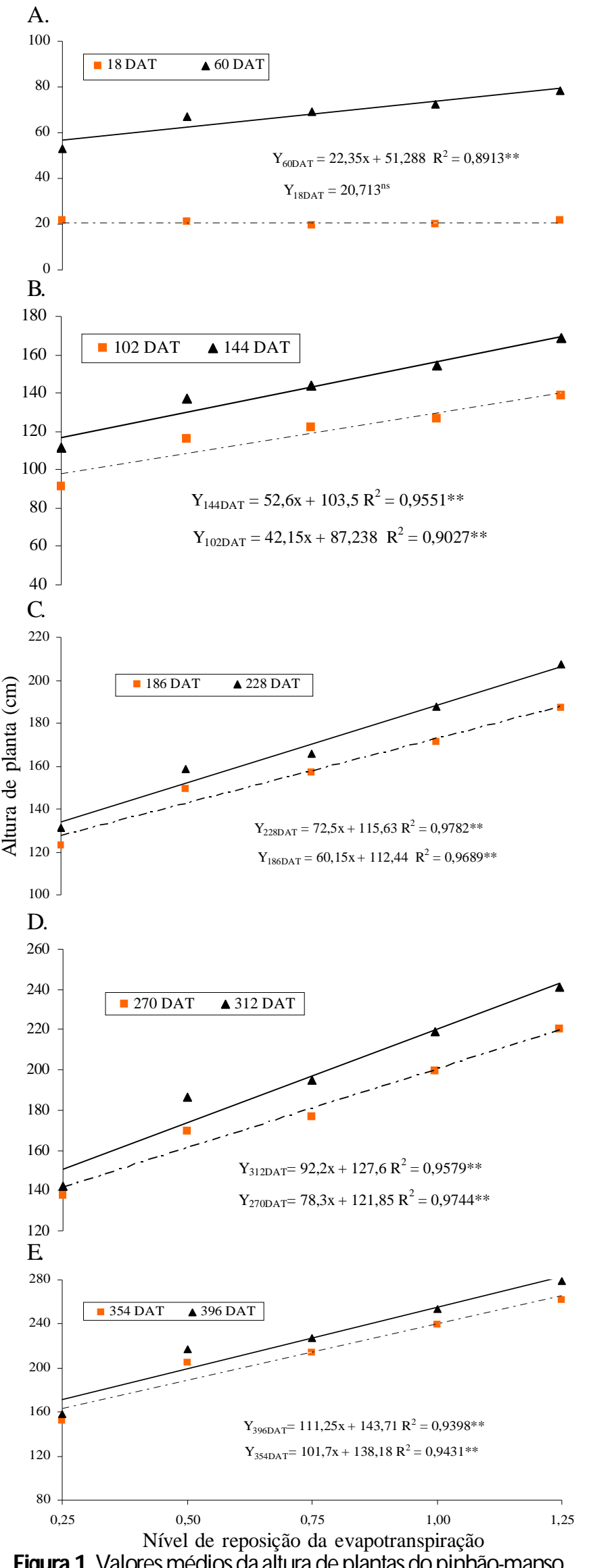

Figura 1. Valores médios da altura de plantas do pinhão-manso aos18 e60 (A), 102 e 144 (B), 186 e 228 (C), 270 e 312 (D) e 354 e 396 DAT (E), em função de diferentes níveisde reposição daETc 
plantas são afetados pelo déficit hídrico e, como o crescimento das plantas é controlado pela divisão celular, seguido de sua expansão, uma quantidade de água insuficiente mantendo células das zonas de crescimento em condições de flacidez, reduz o coeficiente de divisão celular e a expansão de todas as células impedindo, deste modo, o crescimento vegetativo das plantas. Em pesquisas com a cultura da mamona, Barros Júnior et al. (2008), constataram que a altura média das plantas cultivadas sem estresse (100\% de água disponível) aos 180 dias após semeadura, foi de 1,28 m. Rodrigues et al. (2009), utilizando água residuária determinaram, aos 174 DAS, altura média das plantas de mamona de 1,49 m; os autores atribuem tal diferença possivelmente ao aporte de nutrientes da água residuária contribuindo, desta forma para um crescimento maior das plantas.

Albuquerque et al. (2009), avaliando diferentes doses de nitrogênio e níveis de água disponível no solo on solo ponivel ncio dose4 e 396 DAT; c uas necessidades hverificaram, aos 150 DAS, que as plantas de pinhão-manso que apresentaram maiores alturas, foram aquelas que receberam a maior dose de nitrogênio $\left(180 \mathrm{~kg} \mathrm{ha}^{-1}\right)$ e o maior nível de água disponível no solo $(100 \%)$.

No final das observações, aos 396 DAT, havia plantas com altura média de 2,5 $\left(\mathrm{Nr}_{4}\right)$ a 2,8 $\left(\mathrm{Nr}_{5}\right) \mathrm{m}$. Tais resultados corroboram com as informações citadas por Arruda et al. (2004), em que relatam que o pinhão-manso é uma cultura característica de crescimento rápido e atinge altura de dois a três metros quando adultas, podendo alcançar até cinco metros em condições especiais. Ratree (2004), avaliando o crescimento do pinhãomanso na Tailândia, observou que mudas desta espécie atingiram altura média entre 83 e $110 \mathrm{~cm}$, com 14 meses de idade.

\section{Diâmetro caulinar (DC)}

Os níveis de reposição da evapotranspiração promoveram efeitos significativos na variável de crescimento diâmetro caulinar, em todos os períodos estudados. Os dados do diâmetro caulinar (Figura 2), se ajustaram ao modelo linear ( $p<0,01)$. À semelhança da variável altura de plantas, o diâmetro caulinar foi menor nas condições de baixa umidade do solo. Na Figura 2 pode-se observar o crescimento do diâmetro caulinar das plantas, em função dos diferentes níveis de reposição da ETc. Conforme os valores do coeficiente de determinação $\left(\mathrm{R}^{2}\right)$, percebe-se alto índice de associação entre os tratamentos e a variável estudada.

O diâmetro caulinar do pinhão-manso aumentou com a maior disponibilidade de água no solo (Figura 2 A, B, C, D e E). Constata-se, nas dez avaliações, efeito linear positivo e, segundo as equações lineares, estimou-se um aumento de $0,0479,0,1437,0,1963,0,2439,0,2942,0,3117,0,324,0,3474$ e $0,3687 \mathrm{~mm}$, no diâmetro caulinar das plantas, por cada centésimo de incremento da evapotranspiração, respectivamente, para as avaliações experimentais ocorridas aos 60, 102, 144, 186, 228, 270, 312, 354 e 396 dias, após o transplantio. Observa-se, portanto, através desses resultados e nas condições desta pesquisa, que os maiores acréscimos no diâmetro caulinar ocorreram com a idade das plantas.
A.

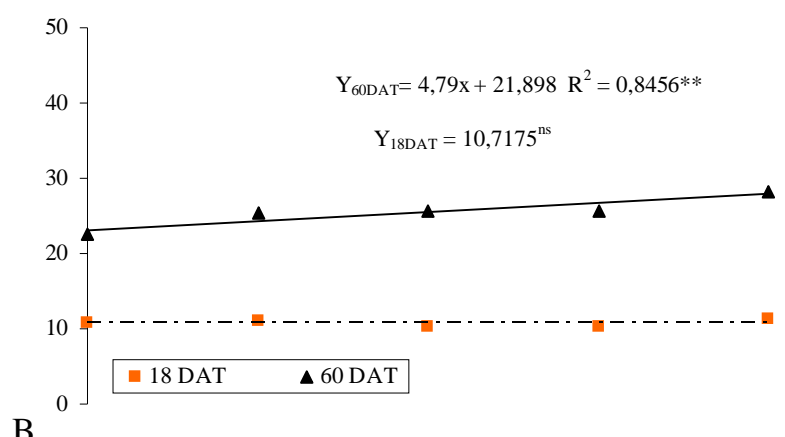

B.

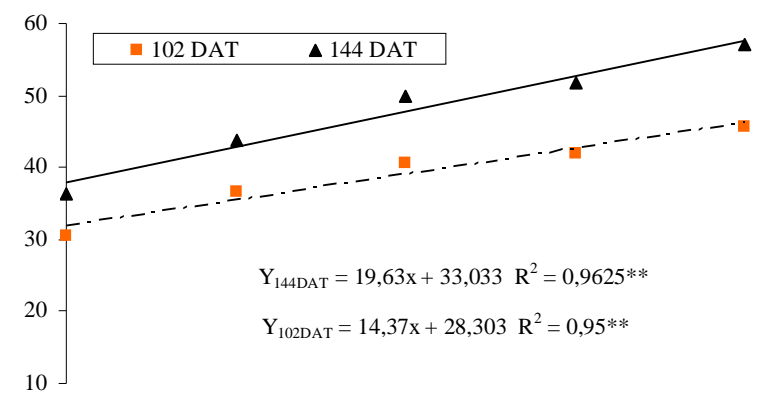

C.

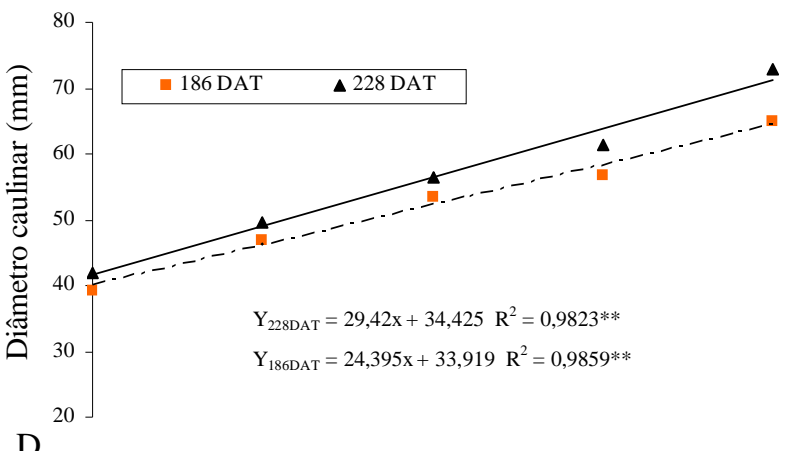

D.

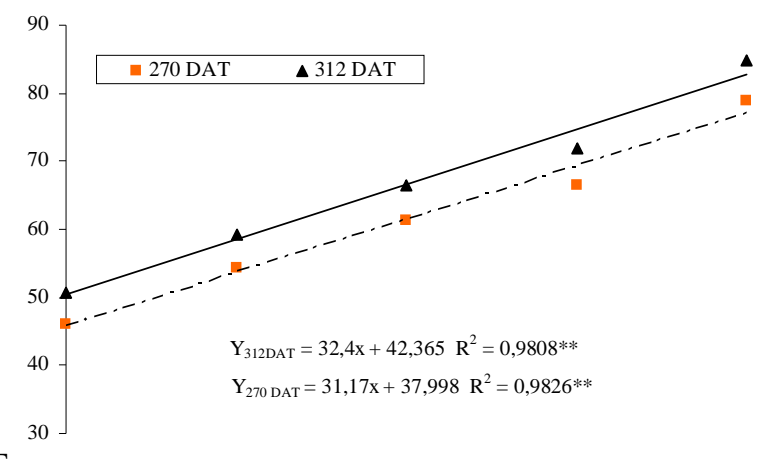

E

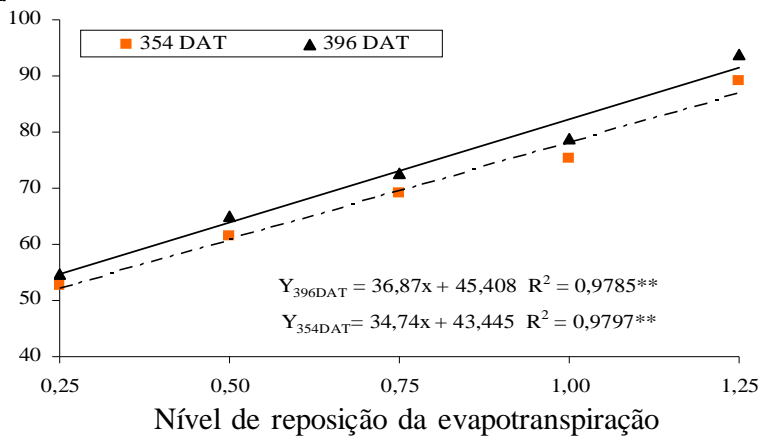

Figura 2. Diâmetro caulinar médio das plantas de pinhãomanso aos 18 e 60 (A), 102 e 144 (B), 186 e 228 (C), 270 e 312 (D), 354 e 396 D AT (E), em função de diversostratamentos 
A sensibilidade do pinhão-manso ao estresse hídrico foi mais acentuada no crescimento em diâmetro caulinar do que em relação à altura de plantas. Albuquerque et al. (2009), avaliando a influência de níveis de água disponível no solo no crescimento em diâmetro caulinar do pinhão-manso observaram, aos 150 DAS, os maiores diâmetros no tratamento com $100 \%$ de AD no solo.

Vale et al. (2006), constataram, na fase inicial de crescimento (30 dias após a emergência), que o diâmetro caulinar do pinhãomanso foi afetado linearmente pela condutividade elétrica da água, com redução de 7,68\% por unidade de $\mathrm{CEa}$; efeito semelhante também foi observado na altura das plantas $(7,85 \%)$.

\section{Número de folhas (NF)}

Observa-se que, para a variável número de folhas (Figura 3), os níveis de reposição da ETc ocasionaram efeitos significativos dos 60 DAT até o final das observações, diferindo estatisticamente a nível de 0,05 de probabilidade pelo teste $\mathrm{F}$, aos 60 DAT e nos demais períodos, a nível de 0,01 de probabilidade. O teor de umidade do solo influenciou, de forma linear e crescente a variável de crescimento número de folhas das plantas de pinhão-manso, Figura 3. Durante toda a fase experimental foram observados nas plantas sintomas de sensibilidade ao estresse hídrico, caracterizando-se por plantas com baixo número de folhas e folhas pequenas. A partir dessas constatações determinou-se o aumento do NF das plantas de $1,12,1,18,1,03,1,41,2,93,3,99,5,70,12,25$ e $32,7 \%$, por cada centésimo de incremento da evapotranspiração, respectivamente para os períodos de 60, 102, 144, 186, 228, 270, 312, 354 e 396 DAT. Comparado aos resultados encontrados para a AP e para o DC, verifica-se que o número de folhas, foi mais afetado, o que pode significar um mecanismo de defesa da planta sob condições de estresse, limitando as perdas de água pela transpiração.

Elevados teores de sais no solo e na água podem levar as plantas às condições de estresse hídrico. Vale et al. (2006), observaram que o crescimento inicial do pinhão-manso (30 dias após a emergência), sob condições controladas, ocasionou redução de $40 \%$ no número de folhas (de 10,0 para 6,0) correspondendo a cerca de $9,66 \%$ por unidade de $\mathrm{CEa}$, sendo mais afetada que a altura $(7,85 \%)$ e que o diâmetro caulinar (7,68\%). Os autores concluíram que o pinhão-manso é uma espécie sensível à salinidade da água de irrigação.

Silva et al. (2005), em estudos com cultivares de mamoneira aos 60 DAS, e Correia et al. (2005) aos 105 DAS com cultivares de amendoim, verificaram redução linear do número de folhas com decréscimo na ordem de 8,0\% por incremento unitário da salinidade da água de irrigação. Nery et al. (2009), verificaram decréscimo no número de folhas das plantas aos 163 DAS, de $9,75 \%$, por incremento unitário da salinidade da água.

Conforme Taiz \& Zeiger (2004), a expansão ou alongamento celular é um processo que depende do turgor; portanto, é extremamente sensível à disponibilidade de água no solo para as plantas; assim, a restrição hídrica limita não só o tamanho mas também o número de folhas; ainda segundo esses autores, as folhas desenvolvem uma cutícula mais grossa para reduzir a perda de água por transpiração; essas medidas aumentam a eficiência de uso de água pela planta. Apesar da característica
A.

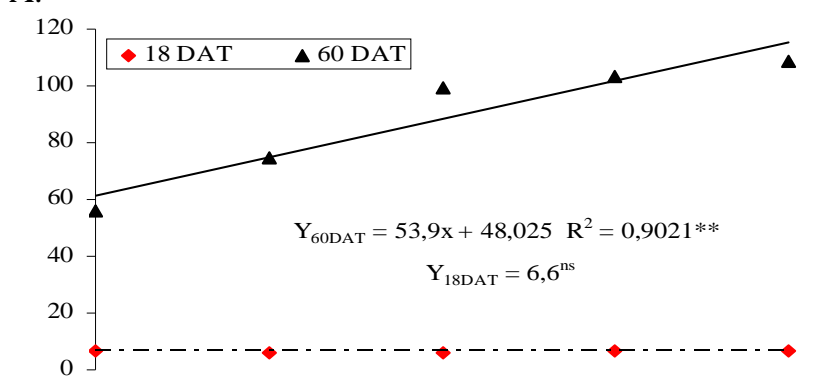

B.

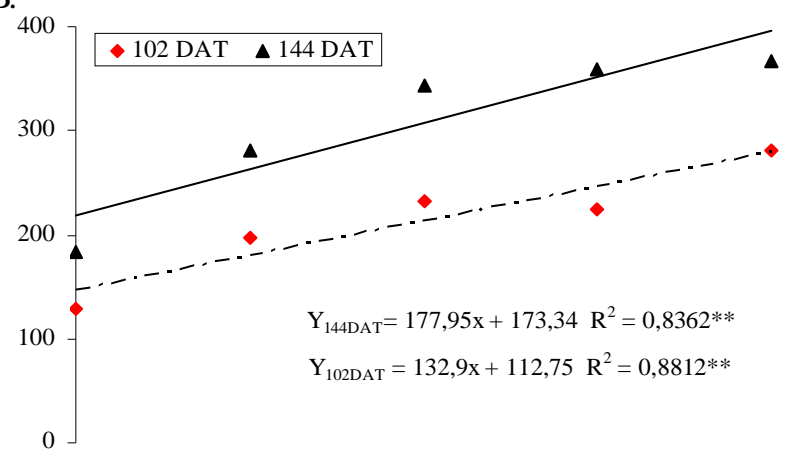

C.
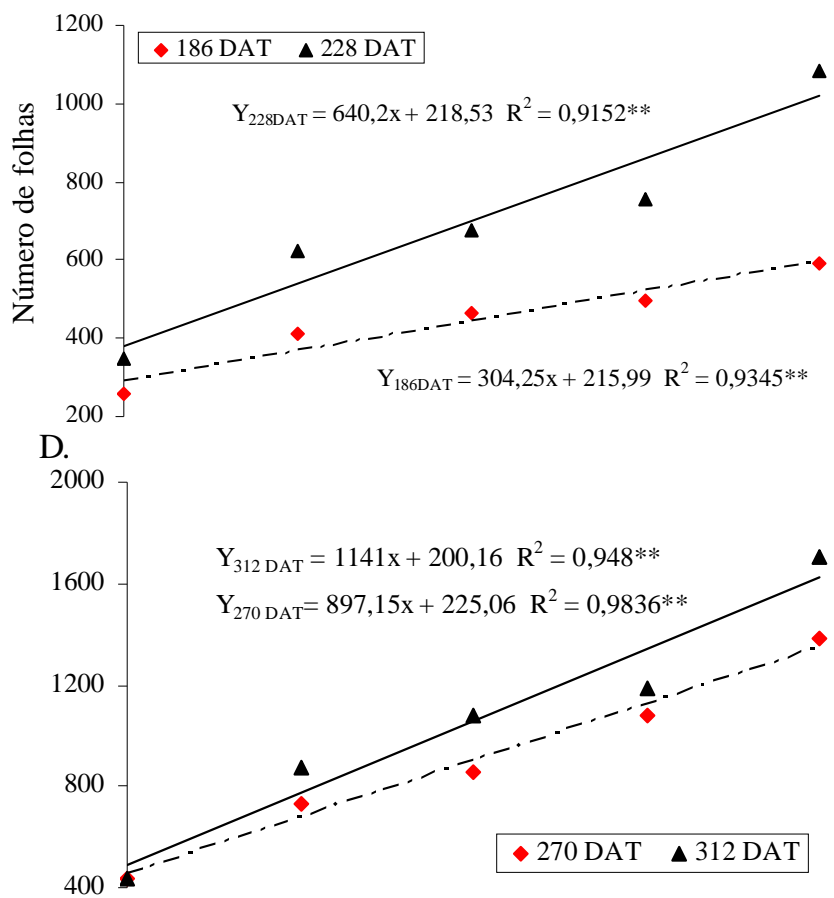

E.

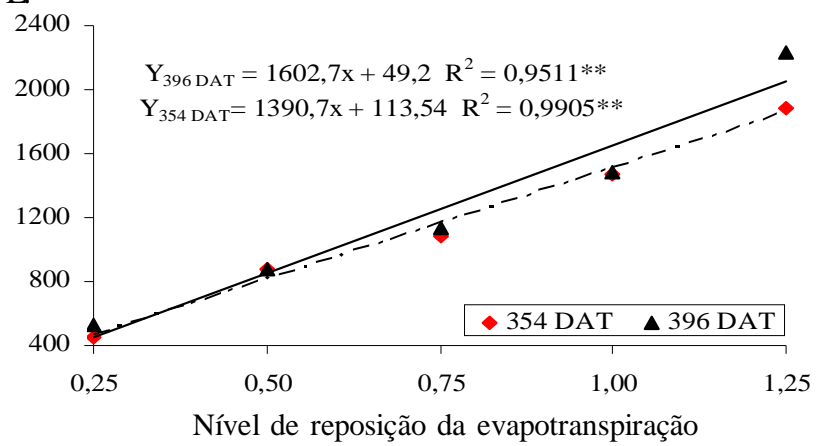

Figura 3. Número médio de folhas do pinhão-manso cultivado sob condições de diferentes níveis de reposição da evapotranspiração, em vários períodos estudados 
de senescência que possui a cultura do pinhão-manso, uma espécie caducifólia, a variação média do número de folhas dos tratamentos com água residuária foi de 88 para 1251 folhas entre os períodos 60 e 396 DAT (Figura 3). Este aumento pode estar relacionado principalmente com a contribuição de nutrientes existentes na água residuária, que favoreceu a melhor nutrição das plantas, no decorrer da pesquisa.

\section{Área foliar (AF)}

Os níveis de reposição da evapotranspiração exerceram efeito significativo sobre a área das plantas ( $\mathrm{p}<0,01)$, em todas as épocas de avaliação (Figura 4). O aumento na área foliar das plantas por cada centésimo de incremento da evapotranspiração foi em torno de $0,008,0,023,0,027,0,047$, $0,065,0,086,0,102,0,130$ e $0,142 \mathrm{~m}^{2}$, respectivamente, aos 60 , 102, 144, 186, 228, 312, 354 e 396 dias após o transplantio (Figura 4). Observa-se, dentre as variáveis de crescimento estudadas na presente pesquisa, que a área foliar foi a mais sensível ao estresse hídrico. Barros Júnior et al. (2008), também verificaram que, quanto menor o conteúdo de água no solo mais precocemente surgem reduções na área foliar da mamoneira.

Taiz \& Zeiger (2004) relatam que plantas submetidas a déficit hídrico desenvolvem folhas menores e mais espessas com o objetivo de minimizar a perda de água por transpiração. Para Bergamaschi et al. (2009), a baixa disponibilidade de água no solo pode provocar redução da área foliar, por secamento ou queda das folhas; trata-se de uma tentativa da planta reduzir a perda de água por transpiração, aumentando a eficiência de uso da água; todavia, isto resulta em queda da fotossíntese total que, por sua vez, reduz a taxa de crescimento e a produção da planta.

Xavier et al. (2009), observaram, em pesquisa com a cultivar mamona BRS Nordestina com águas residuárias tratadas de três indústrias de Campina Grande, PB, que a área foliar apresenta tendência de decréscimo após os 90 DAS. À semelhança das variáveis altura de planta e diâmetro caulinar, o uso do efluente industrial mais rico e equilibrado em nutrientes resultou em maior crescimento em área foliar, notadamente quando as plantas foram irrigadas com os níveis de 80 e $100 \%$ de água disponível. Nas plantas da testemunha absoluta (água de abastecimento sem adubação), o autores verificaram decréscimo acentuado na área foliar, da ordem de $90 \%$.

\section{Número médio de cachos}

Conforme os resultados apresentados na Tabela 3, a componente de produção número médio de cachos das plantas do pinhão-manso, sofreu influência significativa a nível de 0,01 de probabilidade, com a aplicação dos tratamentos. Na Figura 5 se constata que os dados da componente de produção número de cachos se ajustaram melhor ao modelo exponencial. Ocorreu uma variação elevada na produção das plantas, entre os tratamentos $\mathrm{Nr}_{1}$ e $\mathrm{Nr}_{5}$. Com base na equação matemática apresentada na Figura 5, o incremento no número médio de cachos entre os tratamentos $\mathrm{Nr}_{1}$ e $\mathrm{Nr}_{5}$, foi de $648,80 \%$.

Quanto maior o período de tempo disponível para a planta com condições ambientais favoráveis, maior também será o número de frutos formados e, portanto, maior a produtividade. Nesta pesquisa se observou que as plantas apresentavam produção contínua, principalmente aquelas sob situação de disponibilidade de água no solo.

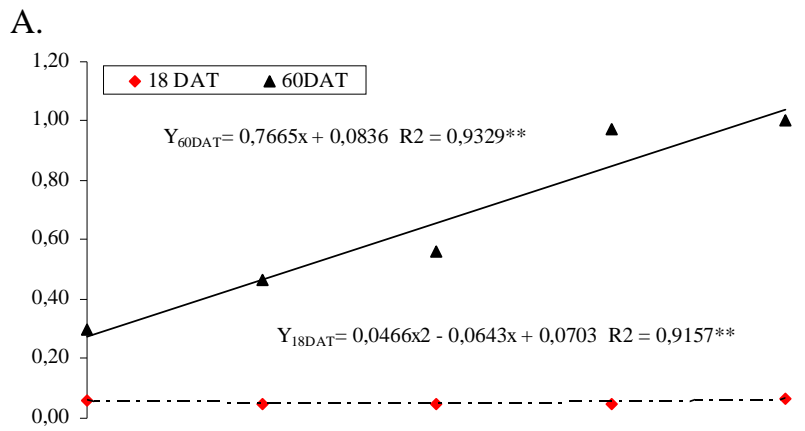

B.
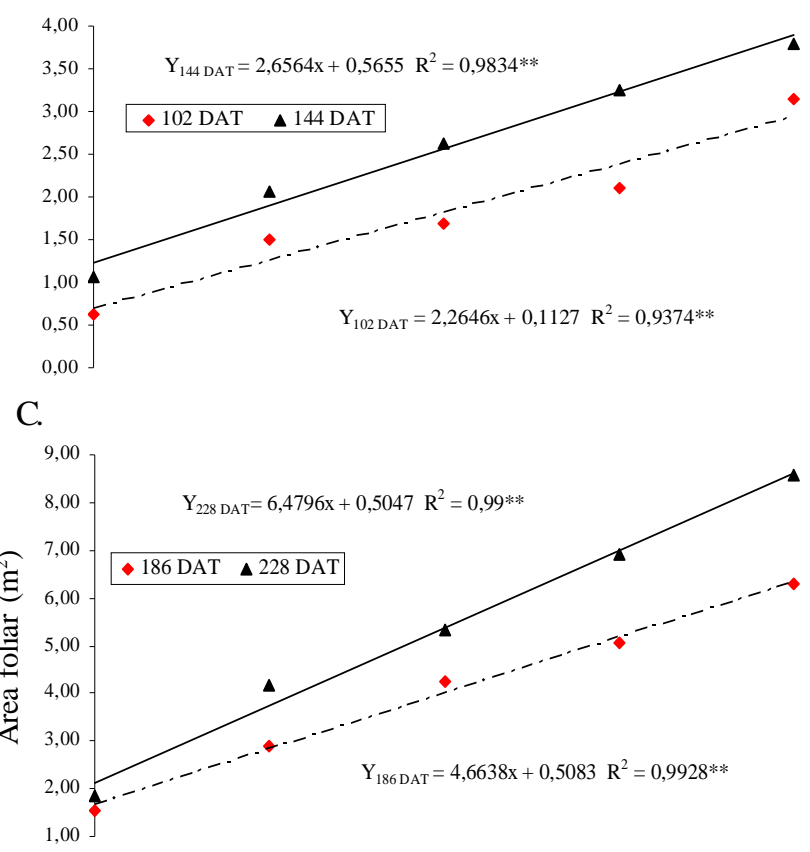

D.

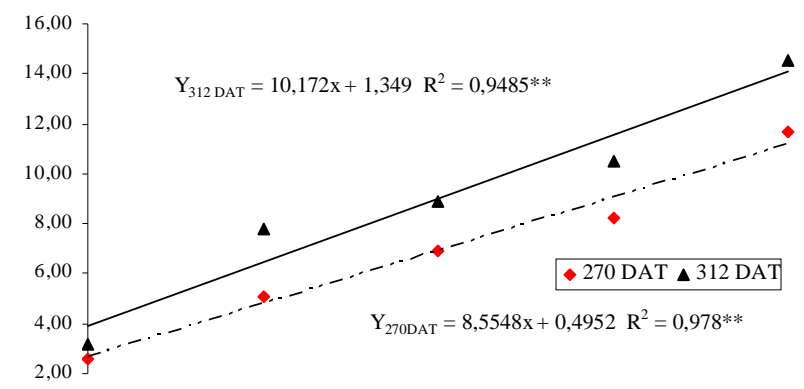

E.

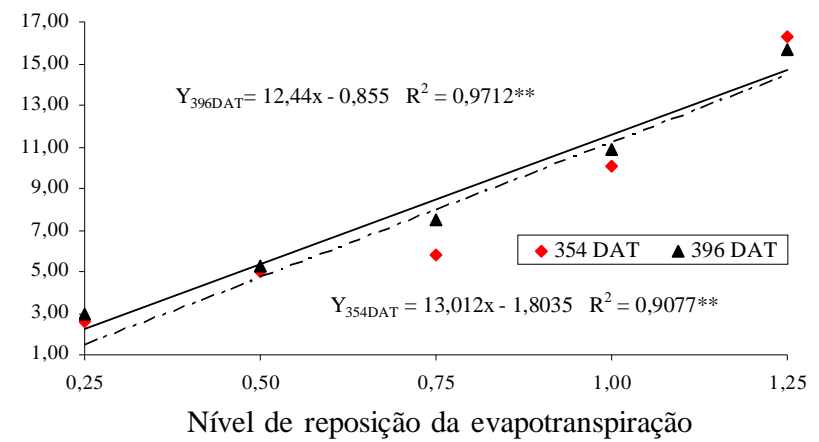

Figura 4. Área foliar média do pinhão-manso, em dez períodos: 18 e 60 (A), 102 e 144 (B), 186 e 228 (C), 270 e 312 (D), e aos 354 e 396 DAT (E), em função de diferentes níveis de reposição da ETC 
Tabela 3. Resumo das anál ises de regressão para o número médio de cachos das plantas de pinhão- manso, durante a produção

\begin{tabular}{lcc}
\hline \multicolumn{1}{c}{ Fonte de variação } & GL & Quadrados médios \\
\cline { 3 - 3 } Nível de rep. (Nr) & 4 & Número médio de cachos \\
Exponencial (X) & 1 & $5360,8937^{* *}$ \\
Blocos & 3 & $20962,3052^{* *}$ \\
Resíduo & 12 & 69,3458 \\
CV(\%) & - & 98,2937 \\
\hline
\end{tabular}

$\left(* *, *,{ }^{\text {ns }}\right)$ Significativo a $1 \%, 5 \%$ e não significativo, respectivamente, pelo Teste $\mathrm{F}$

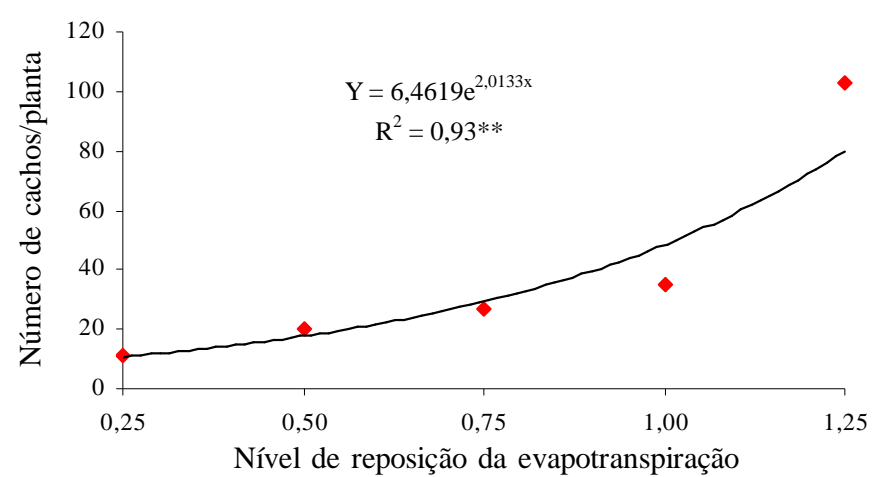

Figura 5. Valores médios do número de cachos sob diferentes níveis de reposição da evapotranspiração durante a produção

\section{Conclusões}

1. Em condições de disponibilidade hídrica a cultura do pinhão-manso, apresentou crescimento e desenvolvimento contínuos.

2. O aumento no suprimento hídrico com água residuária resultou em incrementos lineares na altura da planta, diâmetro do caule, número de folha e área foliar total;

3. A área foliar do pinhão-manso é a variável de crescimento mais sensível ao estresse hídrico.

4. Ocorre aumento de $648,80 \%$ no número médio de cachos entre os tratamentos com 0,25 e 1,25 de reposição da evapotranspiração com água residuária.

\section{LITERATURA CITADA}

Akbar, E.; Yaakob, Z.; Kamarudin, S. K.; Ismail, M.; Salimon, J. Characteristic and composition of Jatropha curcas oil seed from malaysia and its potential as biodiesel feedstock. Scientific Research, v.29, p.396-403, 2009.

Albuquerque, W. G.; Beltrão, N. E. de M.; Freire, M. A. O.; Azevedo, C. A. V. de. Avaliação do crescimento do pinhão manso em função do tempo, quando submetido a níveis de água e adubação nitrogenada. Revista de Biologia e Ciências da Terra, v.9, p.68-73, 2009.

Arruda, F. P. de; Beltrão, N. E. de M.; Andrade, A. P. de; Pereira, W. E.; Severino, L. S. Cultivo do pinhão-manso (Jatropha curcas L.) como alternativa para o semi-árido Nordestino. Revista Brasileira de Oleaginosas e Fibrosas, v.8, p.789-799, 2004.
Barros Júnior, G.; Guerra, H. O. C.; Cavalcanti, M. L. F.; Lacerda, R. D. de. Consumo de água e eficiência do uso para duas cultivares de mamona submetidas a estresse hídrico. Revista Brasileira de Engenharia Agrícola e Ambiental, v.12, p.350$355,2008$.

Bergamaschi, H.; Dalmago, G. A.; Bergonci, J. I.; Bianchi, C. A. M.; Müller, A. G.; Comiran, F.; Heckler, B. M. M. Distribuição hídrica no período crítico do milho e produção de grãos. Pesquisa Agropecuária Brasileira, v.39, p.831-839, 2004.

Beltrão, N. E. de M.; Silva, L. C.; Melo, E. B. Mamona consorciada com feijão visando produção de biodiesel, emprego e renda. Revista Bahia Agrícola. v.5, p.34-37. 2003.

Correia, K. G.; Fernandes, P. D.; Gheyi, H. R.; Gurgel, M. T.; Rodrigues, L. N. Crescimento do amendoinzeiro irrigado com águas salinas. Revista Brasileira de Engenharia Agrícola e Ambiental, v.9, suplemento, p.81-85, 2005.

EMBRAPA - Empresa Brasileira de Pesquisa Agropecuária. Manual de métodos de análises de solo. 2. ed. Rio de Janeiro: Centro Nacional de Pesquisas de Solos, 1997. 212p.

Ferreira, P. V. Estatística experimental aplicada à agronomia. 2 ed. Revisada e ampliada. Maceió: UFAL/EDUFAL/ FUNDEPES, 2000. 437p.

Nery, A. R.; Rodrigues, L. N.; Fernandes, P. D.; Chaves, L. H. G.; Dantas Neto, J.; Gheyi, R. H. Crescimento do pinhãomanso irrigado com águas salinas em ambiente protegido. Revista Brasileira de Engenharia Agrícola e Ambiental, v.13, p.551-558, 2009.

Novais, R. F.; Neves, J. C. L.; Barros, N. F. Ensaio em ambiente controlado. In: OLIVEIRA, A. J.; Garrido, W. E.; Araújo, J. D.; Lourenço, S. (coord.) Métodos de pesquisa em fertilidade do solo. Brasília: Embrapa SEA, p.189-255, 1991.

Ramos, L. P.; Kucek, K. T.; Domingos, A. K.; Wilheim, H. M. Biodiesel: Um Projeto de sustentabilidade econômica e sócioambiental para o Brasil. Revista Biotecnologia, Ciência e Desenvolvimento, v.31, p.28-37, 2003.

Ratree, S. A. Preliminary study on physic nut Jatropha curcas in thailand. Journal of Biogical Sciences, v.7, p.1620-1623, 2004.

Richards, L. A. Diagnóstico y rehabilitación de suelos salinos e sodicos. México: Limusa, 1977. 172p.

Rodrigues, L. N.; Nery, A. R.; Fernandes, P. D.; Beltrão, N. E. de M., Gheyi, R. H. Crescimentoe produção de bagas da mamoneira irrigada com água residuária doméstica. Revista Brasileira de Engenharia Agrícola e Ambiental, v.13, p.825-835, 2009.

Severino, L. S.; Vale, L. S.; Beltrão, N. E. de M. A simple method for measurement of Jatropha curcas leaf area. Revista Brasileira Oleaginosas e Fibrosas, v.11, p.9-14, 2007.

Silva, S. M. S.; Alves, A. N.; Gheyi, H. R.; Beltrão, N. E. de M.; Severino, L. S.; Soares, F. A. L. Germinação e crescimento inicial de duas cultivares de mamoneira sob estresse salino. Revista Brasileira de Engenharia Agrícola e Ambiental, v.9, suplemento, p.347-352, 2005.

Taiz, L.; Zeiger, E. Fisiologia vegetal. 3.ed. Porto Alegre: Artmed, 2004.719p.

Vale, L. S.; Severino, L. S.; Beltrão, N. E. de M. Efeito da salinidade da água sobre o pinhão-manso. In: Congresso da Rede Brasileira de Tecnologia do Biodiesel 1, 2006, Anais... Brasília: IBPS, 2006. p.87-90. 
Villela Junior, L. V. E.; Araújo, J. A. C.; Factor, T. L. Efeito da utilização do efluente de biodigestor no cultivo hidropônico do meloeiro. Revista Brasileira de Engenharia Agrícola e Ambiental, v.7, p.72-79, 2003.
Xavier, J. de F.; Azevedo, C. A. V. de; Beltrão, N. E. de M.; Andrade, A. R. S.; Lima, V. L. A. de. Crescimento da mamoneira sob diferentes tipos de águas residuárias e níveis de água no solo. Revista Ambi-Água, v.4, p.196-210, 2009. 